\title{
Um Corte No Externo: ou, o que pode Édipo-ancião ensinar para artistas da performance?
}

BARROS, Joanna

performer

\author{
"E eu, menos estrangeiro no lugar que no momento \\ Sigo mais sozinho caminhando contra o vento \\ E entendo o centro do que estão dizendo"
}

(Caetano Veloso)

\begin{abstract}
Resumo
Performances artísticas acontecem em espaços fronteiriços/ liminóides, onde o contato e troca com o estranho/estrangeiro não é apenas possível como necessário e desejado. Nossa proposta é olhar para um tipo de estrangeiro e estabelecer relações entre ele, artistas e público em performances artísticas. Escolhemos o estrangeiro "conhecido", o estranho interno, e circunscrevemos nosso estudo a um paradigma de estrangeiro em específico: Édipo.
\end{abstract}

Palavras chave: performance, estrangeiro, Édipo

\begin{abstract}
Artistic Performances happen in border/liminoid spaces where the contact and exchange with strangeness/foreingers is not only possible but also necessary and desired. Our idea for this article is to look at one particular kind of foreigner and establish relations between it, artists and the public in artistic performaces. We chose the known foreinger, the internal stranger and circunscribed our study to one particular foreigner: Oedipus.
\end{abstract}

Keywords: performance, foreigner, Oedipus 
Esse artigo busca explorar o papel de um certo tipo de estrangeiro e de seu valor em performances artísticas. Partimos da hipótese de que numa performance artística existe uma dupla relação - entre o artista e si mesmo e o artista e o público - que é estrangeira/estranha, no sentido de não ser usual, conhecida, habitual.

Exploramos aqui a hipótese desta relação ser um dos fatores que contribuem de forma decisiva para a emergência de novas perspectivas tanto internas quanto externas que carregam a possibilidade de transformação de si/ do mundo.

Para tanto, escolhemos duas peças de teatro que tratam de um estrangeiro em específico: Édipo. As peças são "Édipo rei" e "Édipo em Colono", ambas de Sófocles (496 aC - 406 aC). Ao abordar estas obras, três questões nos parecem fundamentais: o estrangeiro conhecido, o estranho interno e o valor do estrangeiro.

Não se trata de uma análise das peças de Sófocles nem tampouco de um estudo aprofundado sobre Édipo, mas sim de um olhar para certo tipo de estrangeiro que Édipo encarna, e de como observá-lo pode nos ajudar a abordar certos aspectos da performance e seus estados de emergência.

A versão do mito edipiano que escolhemos utilizar neste artigo é a de Sófocles. É o caráter trágico da peça que coloca Édipo literal e metaforicamente nas zonas fronteiriças que desejamos estudar ${ }^{1}$.

A tragédia surge num momento muito particular e "situa, logo de início, o indivíduo na encruzilhada da ação" (Vernant: 2008 pg. 4). Ela surge no fim do sec. VI e início do sec. V a.C. Neste momento começava a discussão social e jurídica sobre a responsabilidade das ações humanas ser algo independente, separado do plano divino e das tradições míticas, ou não. A mera hipótese de que isso fosse possível fez surgir conflitos internos e sociais antes inexistentes.

Édipo, não por acaso, encarna esse conflito. É justamente o contato com o até então, absolutamente desconhecido, que permite a emergência de uma discussão que ia muito além de uma questão pessoal do personagem.

Édipo estrangeiro de si
1.

"nas primeiras versões do mito não há, no conteúdo legendário, o menor traço de autopunição, porque Édipo morre tranquilamente instalado no trono de Tebas, sem ao menos ter furado seus olhos" (Vernant, 2008:56) 
“A peça 'Édipo Rei' conta a história de um homem que matou o próprio pai e casou-se com a própria mãe. Não tinha consciência do que fez. Quando descobre a verdade, arranca os próprios olhos e dedica o resto da vida à expiação." (Francis, Paulo: em "Édipo rei", 1967)

Édipo é um estrangeiro muito particular porque se autoproclama como tal. Depois das relações que o ligavam a seu pai, Laio, e sua mãe, Jocasta, virem à tona ele se cega e se autoexila. Lança-se a terras desconhecidas, lugares sem rei, sem dono, sem lei.

O herói, "do dia para a noite", vira parricida, incestuoso, indesejado e maldito, inclusive por si mesmo. É como se outra pessoa, que paradoxalmente sempre esteve presente, de repente emergisse do próprio Édipo que agora tem que conhecer e conviver com esse estranho interno. Junto com ele, emerge um conflito coletivo que já estava no ar, mas, naquele momento ainda não tinha forma e foi singularizado na peça na experiência de apenas um homem.

O conflito sobre a responsabilidade da ação - tanto do homem como dos deuses - estava na ordem do dia na época em que Sófocles escreveu a tragédia de Édipo. O personagem, ao encarnar esse conflito, não apenas joga-se numa zona de incerteza, como joga ao público da peça neste lugar marginal.

A margem não é fora nem dentro, é um território de passagem, que o Antropólogo Arnold Van Gennep chamou de "limen" ou "threshold", ao fazer a sua classificação de ritos de passagem. O período de margem é o segundo dos três passos do esquema proposto pelo autor - separação, margem, reagregação.

O também antropólogo Victor Turner empresta o termo "limen" de Van Gennep para falar das etapas de crise e reflexão em seu esquema de drama social. Segundo o autor, é no lugar do talvez, "betwixt and between", que as reflexões frente a uma crise podem acontecer.

\footnotetext{
"the limen, or the thresthold, a term I took from van Gennep's second of three stages in rites of passage, is a no-man's-land betwixt-and-between the structural past and the structural future" (Turner, Victor. 1995:11) ${ }^{2}$
}

Um lugar transitório por definição, onde tudo é possível porque nada foi decidido. Espaço de ambiguidades, onde habitam os monstros, hermafroditas, bem e mal, sagrado e profano. Lugar onde Édipo rei e Édipo assassino podem conviver e agir, e um lugar muito parecido àquele no qual acontecem performances artísticas.

Parecido porque não é o mesmo. Turner diferencia o que
2. Tradução da autora: "O limen ou threshold, termo que emprestei do segundo de três estágios em ritos de passagem de Van Gennep, é uma terra de ninguém, entre e no meio do passado e do futuro estruturais". 
chama de espaços liminares (liminal spaces) de espaços liminóides. Os primeiros são os que existem em rituais arcaicos, xamânicos, religiosos. Os segundos existem em sociedades modernas pós coloniais e se assemelham aos primeiros no sentido de constituir por tempo limitado um espaço entre espaços onde uma passagem acontece. $O$ teatro e de forma mais ampla as performances artísticas em sociedades modernas ocorrem em espaços liminóides, que têm um caráter mais reflexivo do que os espaços liminares.

Guardadas estas diferenças, ambos são espaços instáveis, transitórios, contraditórios e de regras suspensas. Lugares onde certo e errado, bom e ruim, e outras dualidades deixam de existir e passam a se indeterminar.

Como diz a autora e teatróloga Érika Fisher Lichte em seu livro "The transformative power of performance", é um lugar onde funciona a lógica da soma, da inclusão, e não a da substituição (Fischer-Lichte, 2008:174) e no qual uma nova estética, a "estética do performativo" pode surgir.

\section{Re-encantamento do mundo}

Neste livro, a autora tem como foco performances pós1960 e, mais especificamente, a troca de papéis entre espectadores e atores (feedback loop), no sentido do que isso pode significar.

\footnotetext{
"When oppositions dissolve into one another our attention focuses on the transition from one state to the next. The space between opposites opens up; the in-between thus becomes a preferred category. Again and again we have seen that the aesthetic experience enabled by performances can primarily be described as a liminal experience capable of transforming the experiencing subject." (Fischer-Lichte, 2008:174) ${ }^{3}$
}

Alguns capítulos adiante, a autora retoma a ideia de transformação do sujeito que participa da performance (espectadores e atores) para falar sobre algo que chama de reencantamento do mundo."By transforming it's participants, performance achieves the reenchantment of the world." (Ibid.: 180)

Mas o que vem a ser o reencantamento do mundo?

A autora o descreve como uma nova forma de relacionar-se consigo mesmo e com o mundo onde ao invés de oposição e substituição existe agregação. Um lugar onde não existe o estrangeiro ou o conhecido, mas os dois juntos e ao mesmo tempo. Um fluxo de diálogo entre ambos passa a ter espaço, indeterminando-os, e isso basta para que algo se transforme.

Esse lugar de fluxo, quando bloqueado, como foi durante
Tradução da autora: "quando oposições se dissolvem uma em outra, nossa atenção se foca na transição de um estado para outro. O espaço entre opostos se abre; e o meio se transforma na categoria preferida. Repetidamente, vimos que a experiência artística proporcionada pela performance pode primeiramente ser descrita como uma experiência liminar capaz de transformar quem passa por ela"

Tradução da autora: "ao transformar seus participantes, a performance re-encanta o mundo" 
anos no caso de Édipo, pode, ao invés de transformação causar destruição. Lembremos da peça, nela, Édipo não procurou conhecer o estranho assassino que o Oráculo enxergara, ao invés disso ele fugiu, tentando levantar um muro interno que o protegesse de quem ele não queria ser. Esse muro impedia que homem se conhecesse.

O diálogo precisa de terreno, e se ele não existir, o processo é frustrado, e o que emerge acaba sendo tão somente um jorro de algo que permaneceu apartado até a hora em que explodiu: o suicídio de Jocasta, a cegueira de Édipo, o horror diante do estranho e a necessidade de seu extermínio.

Buscar terrenos de emergência do diálogo com o estranho é, portanto, vital.

A procura por lugares onde pode acontecer esse contato é lenta. Uma das táticas usadas por muitos artistas é a de viajar. Não importa se a viagem é curta ou longa, se ela é dentro da própria cidade ou se é para um país distante. O que importa é o olhar durante o caminho. No entanto, a condição de estrangeiro não nasce com o mero deslocamento.

Ainda que viajar ajude - a mudança de ambiente sempre cria certo estranhamento inicial - isto não garante a eficácia do processo. Muitas vezes, ficar onde se está, e desenvolver técnicas para perceber o mesmo lugar de maneiras distintas, é um caminho, menos sedutor, talvez, mas mais consistente. No caso das artes do corpo a pesquisa acontece no corpo, em suas relações internas e com o ambiente. Os espaços que se quer abrir estão, inicialmente, no corpo, e o que interessa, nesse sentido, é buscar caminhos, pesquisar novas possibilidades de fluxo, de movimento. Um bom exemplo é o da técnica Klauss Vianna.

\begin{abstract}
"A criatividade exige espaço. Sem espaço interior não é possível exteriorizar nossa riqueza expressiva nem criar novos códigos de comunicação artística ou cotidiana. É por isso que procuro desestruturar meus alunos desde o início das aulas."
\end{abstract}

(Vianna, 2005: 137)

Porque desestruturar abre espaço?

Desestruturar um lugar implica em agir em suas relações (internas e externas) de modo que os padrões que emergem destas relações sejam flexibilizados. Isto permite o surgimento de novas relações e novos padrões. O que, por sua vez, acarretaria uma mudança de estados corporais.

Algo se transforma, e esta transformação se dá por um processo que começa no olhar, não apenas para fora, mas para dentro, na percepção de si, do espaço, e das relações internas e externas existentes. 
No caso da trilogia edipiana, Édipo teve tempo, muitos anos, uma vida inteira para relacionar e conhecer o estrangeiro que emergira e que finalmente tinha voz.

A fala/ação do estrangeiro ou de si

"O Édipo em Colono é uma tragédia da passagem. Vê-se Édipo, tendo ultrapassado as fronteiras, instalar-se sobre uma fronteira, em seguida, inocentado pela Peitho, a santa da persuasão que o anima, passar de Atenas para um outro mundo. Tentei mostrar aqui que, até no detalhe da encenação, a tragédia se refletia nas fronteiras, as que separam os homens e também as que lhes permitem se reunir" (Vernant, 2008: 315)

O que aconteceu durante os anos de exílio, anos de estrangeiro, de Édipo? E o que acontece logo antes de sua morte?

No caso da peça, um dos processos importantes que parece ter ocorrido durante o período de exílio foi sua remissão. $O$ sentido mais óbvio desta palavra é o de perdão dos pecados, da doença, ou da dívida. No caso da peça, o perdão - ainda que essa palavra não seja usada de forma explícita - parece ser, em primeiro lugar, de si. Algo que só se dá internamente.

Édipo chega a Colono já sabendo de seu valor, que está atrelado, ao que parece, ao fato de ele ter perdoado suas ações passadas. Ele chega, inclusive, já tendo os argumentos para sua defesa. O mais forte deles é a ausência de culpa, que neste caso se mistura com responsabilidade, por falta de intencionalidade da ação.

"Édipo: (...) Se ataquei meu pai - não nego que o ataquei -, levantei meu braço e o matei sem saber o que fazia nem contra quem, como podes denunciar um ato involuntário como se tivesse sido intencional?" (Sófocles, 2010:95)

Usamos palavra remissão também por seus outros significados. Remissão remonta ao verbo remir. Este, entre outras coisas, significa resgatar, readquirir, libertar do cativeiro. Nosso interesse é no processo de resgate/saída do cativeiro, que ocorreu no período de exílio de Édipo, período em que ele era estrangeiro.

Para abordar esse aspecto precisamos antes lidar com duas perguntas: Édipo foi cativo do que/de quem? Como tornar-se estrangeiro permitiu que essa condição mudasse? Mais do que os pormenores da história, olhando para sua estrutura de relações, pode-se encontrar linhas que permitem, ao menos, tocar essas questões e relacioná-las com a condição do artista em performances. 
Édipo, sem saber, mata o pai e esposa a mãe. Ao fazê-lo, comete crimes de forma não intencional. Quando a verdade emerge ele se cega, e é maldito pelos cidadãos de Tebas e seus governantes.

Em outras palavras, o olhar, tanto público quanto interno, é de horror, de completa estranheza, a impressão é que nada há em comum entre o herói e o assassino. Ele é punido por si e pelos demais pelos atos que cometera, ainda que não intencionalmente. E mais, sua nova condição (nova não no sentido de nunca ter existido, mas de ter apenas agora emergido) afeta suas ações e decisões passadas, estendendo-se a seus filhos.

Pode-se ser cativo de um tipo de olhar?

Aceitar a existência de diferentes maneiras de enxergar algo que até então era visto de uma forma específica não é um processo fácil. A tragédia, como já mencionado, surge num momento particular, em que se questionava a responsabilidade dos atos do homem. Era o início desse questionamento e ele foi marcado por um conflito interno entre o homem e os Deuses. Para uma sociedade que até então encontrava no divino a razão das ações humanas, conceber a possibilidade de que isto não fosse assim deve ter sido muito difícil.

Essa dificuldade é refletida na peça. O drama de Édipo não é só dele. Ele, assim como os demais, era cativo de uma visão de mundo que, até o início do sec. $\mathrm{V}$ a.C., não tinha sido colocada em discussão, ou pelo menos não nas proporções de agora.

As três peças da trilogia Tebana dão vulto a esta crise, mas é em "Édipo em Colono" que ela é exposta mais claramente, levando em conta a voz do oráculo, de Édipo, seus filhos, do rei e do povo. Numa primeira leitura pode-se pensar que Édipo é recebido por Teseu e pelos cidadãos de Colono apenas por conta das previsões do oráculo, que diziam que quem o recebesse teria força.

No entanto, há também a hipótese de uma outra origem para o acolhimento de Édipo, que é justamente o fato de ele ter exposto publicamente um conflito interno, fazendo com que este, finalmente se tornasse visível, e permitindo que a questão, que não ia se resolver ali, ganhasse espaço para ser discutida.

O tempo em que caminhou errante na "condição de semcidade" (Ibid.: 114) contribuiu para que ele transformasse a forma como via os acontecimentos, bem como suas próprias ações e a si mesmo. Mudar o jeito de olhar para alguma coisa transforma a própria coisa, ou melhor, a faz emergir. Édipo 
não era mais cativo de uma forma de ver o mundo, e nisso liberta-se de uma visão das coisas até então dominante.

O olhar do cego sem pátria pôde dar palavra ao que antes não tinha forma e isso re- encantou o mundo não apenas para ele, mas para todos os que também conviviam com esse conflito disforme. Ele joga o público (os cidadãos de Colono e os espectadores da peça) numa zona de regras ainda por construir, um lugar indefinido e ambíguo onde não existe uma resposta certa ou errada. Uma situação de suspensão, que põe em questão a própria ação humana. O que fazer? Terreno de emergência.

O processo de alguns artistas, especialmente os que se dedicam as artes do corpo, se assemelha bastante ao processo do velho Édipo. A performance é uma linguagem que se dedica ao contato com o estranho. Apesar de já ocupar um lugar menos marginal, coisa que aconteceu apenas nos últimos anos, ela ainda representa uma linguagem que vai a extremos, muitas vezes ao limite do psicofísico. Mutilações, alterações de estados corporais por meio de processos psicofísicos que podem ou não envolver ingestão de drogas, operações permanentes, imagens grotescas, homem-mulher-bicho arte e vida, sem palco, sem personagem.

Ela age como resistência às construções de muralhas entre o estrangeiro e o conhecido. Muralhas estas que vêm sendo sistematicamente construídas. Sejam elas concretas, como as do metrô de São Paulo que murou a parte externa onde passavam os trens para que torcedores não enxergassem nada no caminho para o novo estádio (para citar um exemplo mais banal e recente), sejam elas mais sutis, tão antigas que vêm de não se sabe onde nem quando, talvez de mais de 500 anos atrás, e que seguem existindo.

Na performance, dentro e fora se misturam num espaço topológico como o da fita de Moebius que Lygia Clark utilizou na sua ação "caminhando"s. Nela, o dedo que acompanha a fita começa num lugar e termina no seu avesso sem ter deixado um minuto de tocar a superfície do papel. $\mathrm{Na}$ ação proposta pela artista, o caminho que se constrói dentro simultaneamente se faz fora. Da mesma forma dentro e fora se misturam na fala de Édipo-ancião ao se dirigir aos habitantes de Colono, e se misturam em espaços liminóides onde acontecem as performances.

Conhecer e conviver com alteridades internas e externas até que elas ganhem vulto e voz em um espaço temporário e por construir é tarefa árdua, vital e que requer rigor (o que não quer dizer rigidez).
5.

"(Se utilizo uma fita de Moebius para esta experiência é porque ela quebra os nossos hábitos espaciais: direita-esquerda, anverso-reverso etc. Ela nos faz viver a experiência de um tempo sem limite e de um espaço contínuo.)" (Clark, Lygia, 1964: pg. 2) 
Numa época que funciona cada vez mais pela lógica da exclusão e da separação, a importância dos estranhos de dentro e de fora e do diálogo com eles não é apenas para artistas, mas para todos. Édipo nos ajuda a ver nesse diálogo a origem do valor e liberdade tanto de si, quanto do estranho que agora também é ele. 
CLARK, Lygia. Caminhando. 1964. Disponível em http://www. lygiaclark.org.br/arquivo_detPT.asp?idarquivo=17/ acesso em 18 jul. 2014

FISHER-LICHTE, Érica. The transformative power of performance. NY: Routledge, 2008

ROLNIK, Suely. O retorno do corpo-que-sabe. Disponível em: http://hemisphericinstitute.org/hemi/pt/enc13-keynote-lectures/ item/2085-enc13-keynote-rolnik/ acesso em 18 jul. 2014

SCHECHNER, Richard - liminal and liminoid. Disponível em https://www.youtube.com/watch?v=dygFtTWyEGM/ acesso em 18 de jul. 2014

sÓFOCLES. Édipo em Colono/Sófocles. Tradução de Donald Schuler. Porto Alegre: L\&PM, 2010

. Édipo Rei/Sófocles. Tradução de Mário da Gama Kury. Rio de Janeiro: Civilização Brasileira S. A., 1967

. A Trilogia Tebana/Sófocles. Tradução de Mário da Gama Kury. Rio de Janeiro: Zahar, 2009

TURNER, Victor. Are there universals in myth, ritual and drama?. In By means of performance. NY, Cambridge University Press, 1995

VAN GENNEP, Arnold. Os ritos de passagem. 2.ed. Petrópolis: Vozes, 2011

VERNANT, Jean Pierre. Mito e tragédia na Grécia antiga / JeanPierre Vernant e Pierre Vidal-Naquet. São Paulo: Perspectiva, 2008 VIANNA, Klauss. A dança. São Paulo: Summus, 2005

VIEIRA, Jorge Albuquerque. Sistemas e Significação, em Feldes, H. P. M. (Org.), Produção de Sentido - Estudos Transdisciplinares. Caxias do Sul: EDUCS/Nova Prova Editora/ Anna Blume, 2003, p. 341-356. 